\title{
ethic@ \\ RULES AND PRIVACY: REMARKS ON PHILOSOPHICAL INVESTIGATIONS §202
}

\author{
NICK ZANGWILL ${ }^{1}$
}

(Hull University, England)

\begin{abstract}
I first distinguish issues about rules and issues about language in Wittgenstein. I then I distinguish private and private rules and argue that there can be private rules because norms of reasoning are private rules. I suggest that Wittgenstein may have equated rules with public rules. I end with reflections on private language.
\end{abstract}

Key words: Rules privacy. Wittgenstein.

$\$ 202$ And hence also 'obeying a rule' is a practice. And to think one is obeying a rule is not to obey a rule. Hence it is not possible to obey a rule 'privately': otherwise thinking one was obeying a rule would be the same thing as obeying it.

Negative conclusions about private language are widely supposed to derive from Ludwig Wittgenstein's discussion of rule-following and the impossibility of following a rule privately. I argue that this is incorrect as an interpretation as well as being implausible on independent grounds.

\section{Language and Rules}

In $\S 202$, Wittgenstein clearly says that it is not possible to follow a rule privately (Wittgenstein 1953; all Wittgenstein references will be to this work). Does this not commit him to thinking, as the standard interpretation has it, that private language is impossible? (Saul Kripke thought so in his 1982.) Many commentators say that the 'real private language argument' occurs in section $\$ 202$, not later. So it is all over for private language in $\$ 202$. But this is only so given the assumption of a strong connection between language and rules. This we should examine.

Does language always involve rules? What does Wittgenstein think is the connection between language and rules? My view is that neither is obvious. If language does always involve rules, it quickly yields an anti-private language view, as follows: 
It must be possible to follow rules.

We cannot follow rules privately.

Language is constituted by rules.

We cannot privately follow the rules that constitute a private language.

So language cannot be private.

But a premise here is that we understand language by following rules. And this is not obvious.

Of course in some minimal sense Noam Chomsky has shown that there are grammatical rules that we all follow in understanding language (Chomsky 1966). But these general grammatical rules falls far short of what words mean (for example that 'dog' means dogs). So the necessity for Chomskyan grammatical rules that are common between very different languages does not mean that following such grammatical rules could constitute understanding the meanings of words.

\section{Rules, Public and Private}

What is a rule? What does Wittgenstein means by a "rule", or by "Regel" in German? A rule, at its most basic, is at least a two-term conditional relation. The antecedent is a fact, the consequent is either a prescription, or an act with a deontic property (Boghossian 2012): it says "If $\mathrm{X}$ then do Y"; or "If $\mathrm{X}$ then you ought to do $\mathrm{Y}$ ". Or the consequent could be a negative prescription or negative deontic fact.

What is 'privacy'? The issues over private languages, private mental states and private rules seem all to be distinct. I shall return to make various distinctions in the next section, but for now I want to characterize a minimal sense of 'privacy' as characterizing mental phenomena that have no observable ('outer') causes or effects by which another person may know them.

How then does Wittgenstein get to his negative conclusion in $\$ 202$ about the impossibility of following a rule privately?

Let us put language to one side for a while and just focus on rules: why should we agree with Wittgenstein that rules cannot be obeyed privately. In particular, why can there not be private rules? Wittgenstein might be right in $\$ 202$ that public rules, interpersonal ones, cannot be obeyed privately. But if there are private rules then surely those rules can be obeyed privately.

Now in many cases _ of the sort Wittgenstein discusses in the earlier part of the Philosophical Investigations — one person follows another person's acts or marks on paper or 
one person is following some previously established social regularity $(\S 28, \S 48, \S 143, \S 145$, $\S 149, \S 156, \S 162$ and $\S 172)$. And it seems to be on the basis of these examples that Wittgenstein concludes that one cannot follow a rule privately, in $\$ 202$. But why should all rules be of that public inter-personal kind? Wittgenstein seems to work with a one-sided diet of examples! If I have counted right, only one example is not interpersonal: one might follow the rule of copying one's own previous marks $(\S 175)$. And even in that case, the marks one has to copy are physical perceivable marks, and the marks made after copying are also physical perceivable marks.

The more radical question is: why cannot some rules just concern what happens in our minds, where there is no behavioural manifestation of following the rule? For example, suppose someone makes a rule: think of an elephant if you think of a kangaroo. That is different from the rule: think of sheep whenever you think of an octopus. Or, what about the rule: if you think of a number, divide it by 2 ? These are private rules, it seems. Surely I can obey such rules privately, and no one can know that I have obeyed the rule, unless I tell them. It is a private rule, and such a rule is to be obeyed privately. Contra $\$ 202$, thinking I have followed such a rule is not at all the same thing as actually following the rule. These are distinct despite the lack of public, interpersonal check. Thus what many see as a central claim of the whole Philosophical Investigations seems plain implausible.

This point can be strengthened. The examples of private rules that I have just given are of trivial rules. But many private rules, at least if rules are norms, are not trivial rules (like the rule to think of an elephant if you think of a kangaroo). Consider reasoning-practical or theoretical. It is not implausible that reasoning just is conducting our minds in accordance with private rules, rules that say what is rational. Some philosophers are attracted to the idea of the normativity of the mental. Such an idea says that there are rational norms binding us in virtue of the propositional attitudes that we have. (See for example Zangwill 2005, 2010.) And in reasoning we respect these norms. Furthermore, many people think that understanding logical constants is constituted by following the introduction and elimination rules that characterize the constants (Wittgenstein 1932-33, section 2, Genzen 1935, Strawson 1952, p. 56, Kneale 1956, Hacking 1979). But the norms of rationality or logic are private rules, which we typically follow privately. Obeying such a rule is a private mental act of forming beliefs or intentions. These rules are not interpersonal rules, and they can be, and often they are, obeyed privately. I suppose they could in principle be obeyed with some outer behavioural manifestation such that another person could know the mental act expected by perceiving the outer behavior of the person following the rules. Perhaps some people's 
eyebrow twitches when they perform modus ponens and their nose twitches when they perform disjunctive syllogism. But in many cases, most cases, there is no outer perceivable manifestation of the rule-following that constitutes rationality or logical reasoning.

Since there is reasoning, there had better be such private rules - not just possibly but actually. And we had better actually follow them at least for much of the time.

The idea of such rules has a good philosophical pedigree. Consider what Descartes called 'Rules for the direction of the mind'? And following Descartes, Kant also commits us to rules of theoretical and practical rationality. They are central to his Critique of Pure Reason. For both these thinkers, without private rules and private rule-following, there would be no knowledge and no reasoning and no logic.

It seems clear that these are private rules that can be obeyed privately. This just looks like an oversight on Wittgenstein's part-a large over-sight. What can Wittgenstein have been thinking?! Granted - it is not possible to obey a public rule privately! But there is nothing inherently public about rules. What Wittgenstein says seems not just implausible as a generalization, but deeply wrong when we consider private rules that are not odd or frivolous, but the rules of rationality or logic that are central to our being who and what we are.

Someone might reply - contrary to Descartes and Kant-that there are norms of rationality, but not rules. However, even if the norms of rationality are not rules, surely we can upgrade them into rules, as Descartes did, and as do many decision theorists and Baysean epistemologists. Then these norms can become private rules, even though the principles themselves are merely norms for most of us. Having upgraded, it is possible to obey these rules privately. I can just reason well or badly, according to the internalized rules, without making a public song and dance about it. Of course, when I come to act on such reasoning, in the sense of making bodily movements not merely mental acts, then others can come to a justified view about my reasoning processes. But we might or might not make bodily movements as a result of reasoning. That is, having recognized the norms, we may articulate them in rules, which are private rules, followed privately. Why not?

\section{3 'Rules' and 'Privacy'}

Or is there a stronger sense of 'privacy' in which rules of rationality or logic are not 'private' in that stronger sense? Let us look more closely at what 'privacy' might mean in the context of rule-following. 
'Privacy' can be characterized metaphysically, in terms of the nature of something, or epistemologically, in terms of what we can know about it. I prefer a metaphysical characterization that has epistemological consequences. Something is not metaphysically 'private' if and only if it has physical causes or effects and (here comes the epistemology) it is knowable by observing those causes and effects. If a thing is private, another person cannot know or understand the thing since the only way it can we know is by observing its causes and effects. This unknowability may be taken in a weak sense, where we add the rider "unless the person tells them". Or this may be taken in a strong sense in which another person cannot know and understand the thing and there is no possible way for the first person to communicate it to a second person. Thus, there are weak and strong senses of 'privacy'.

A sensation or feeling may clearly be private in a weak sense (see §272). We may not tell another person what our sensations or feelings are, for example. But it may also be impossible for someone to know what experience is being had if they have never had a similar experience. That is a stronger kind of privacy. Such privacy is relative to observers. For example, perhaps it is impossible for those who have given birth to explain what it is like to those who have not given birth. So both weak and strong senses of privacy apply to some sensations and other feeling states. Many sensations and feelings, of course, are not weakly or strongly private; but many others are weakly or strongly private.

In the case of private language, there is a strong epistemological notion of privacy in play according to which another person cannot, in principle, understand a private language. However, in the case of private language too, the modal definition cannot be fundamental. It must hold in virtue of the nature of the states in question. It is not possible to know the language because it is about private states. The emphasis placed on possibility in discussions of private language is puzzling. Possibilities are usually not interesting in philosophy apart from what they tell us about actuality. But this has not been heeded in discussions of private language, where the possibility takes centre stage. We need to ask: in virtue of what would it not be possible for another to understand a private language? I propose, we answer: in virtue of a) being about a felt state with no standard observable causes, behavioural effects or manifestation; b) there is no actual language for those states is in place; and c) the introduced meanings are fixed to the felt state introspectively. These are why it is not possible for another to grasp the meaning.

What is the analogue of privacy for mental states and private language for rulefollowing? Perhaps this: rule-following that is private has no causes, or behavioural effects or manifestation by which another person can know whether or not the rule has been followed. 
What would be the weak/strong distinction here? A strong sense of 'privacy' would be that another person could not in principle know whether or not the rule has been followed, and the rule cannot even be explained to others. Moreover, it would be in virtue of what it is to follow a private rule that another person cannot know in principle whether the rule has been followed or even understand it?

Let us now recall the distinction between private and public rules? The idea of following a public rule inwardly, and independent of observable manifestations does disappear, since the rule dictates observable actions. What on earth could be a private act of following a public rule? So public rules cannot even be weakly private.

But what of private rules? When we follow either trivial private rules or rules of reasoning or logic, obedience is a mental act that may or may not have a public observable manifestation. So private rule-following is not impossible, unlike public rule-following. Private rules may be weakly private. Private rules may be followed privately and no one else may know. But what of the strong sense of privacy, where it is impossible to know if the rule has been followed, and we cannot even explain the rule to others? Surely we can know whether others have reasoned well and logically, and we can explain the rules of rationality and logic to others. So in that sense, these rules are not strongly private. The idea that such rules are unintelligible to anyone else is unintelligible. So private rules are weakly but not strongly private.

\section{Public Rules}

Is there any reason to think that a strong and not a weak notion of 'privacy' is in question in $\S 202$ (unlike $\$ 258$ )? In the last section, we found it hard to believe that a strong sense of privacy is in question when Wittgenstein denies that we cannot obey a rule privately. So suppose that Wittgenstein is saying that we cannot follow a rule, any rule, privately, in a weak sense. But as we also saw, that seems like an implausible claim since it runs up against the existence of trivial mental rules and rules of reasoning and logic.

The only hypothesis I can think of is that by "rules", or " Regelen", Wittgenstein just means public rules. (I put aside the completely implausible hypothesis that Wittgenstein is some kind of behaviourist.) This hypothesis would explain why at \$202 Wittgenstein suddenly makes what otherwise seems to be a complete non-sequitur, to conclude that one cannot obey rules privately, on the basis of considering only examples of public rules and no private rules. Of course, there must be observable behavioral manifestations of following public rules. Consider obeying an order, a public order, such as 'Right turn!'. It cannot be 
obeyed inwardly. A soldier on parade cannot obey the order to turn right inwardly or privately, just in his mind by mentally turning right. He must actually turn right. Otherwise there would be no distinction between actually mentally turning right and seeming to oneself that one is turning right. That seems to be what Wittgenstein is thinking. If this is right, rules just are by definition public rules, for Wittgenstein.

But this is strange. Consider orders. I can also obey the order: think of a number between one and ten. That order must be obeyed privately. What goes for orders goes for rules. There are public rules and private rules, just as there are public and private orders. And following and obedience should be public in one case and private in the other.

We can argue as follows. If something can be ordered, it can be made into a rule. I can be ordered to think thoughts or imagine things with no behavioural expression. Therefore there can be private rules. A real example: people in religious orders are ordered not to think lustful thoughts. Such rules are private rules, and obedience to them is private. Obedience is inner obedience. God sees: no one else does.

But if 'rules', for Wittgenstein, are by definition public rules, as on my hypothesis, then it would mean that not all norms correspond to rules. A rule is more than an ought. And while all rules are normative, in a very general sense, not all norms are rules. Hence, it could be, given what rules are, that rules are necessarily public rules, and following a rule depends on a public practice or custom, which is publically observable, as Wittgenstein says at $\$ 202$. That makes some sense of the fact that we can raise the puzzling issue of whether a public rule could be obeyed only once or whether there must be a wider social practice with regular obedience (§199 and §200). Such a practice or institutional theory of public rules seems plausible. But if so, what about norms of reasoning? It may be suggested that there are norms of reasoning but no rules of reasoning, in this sense. If so, Wittgenstein's argument has less reach than it has been taken to have. If we give Wittgenstein a special limited public sense of 'rule', which he needs for $\S 202$ to be remotely plausible, then the implications of what he says are far less than have been supposed. In particular, there are no negative implications for private language, or private mental states. (Certainly there is no basis for attributing any critique of 'Cartesianism'.)

I distinguished public and private rules. Perhaps rules of rationality are not really rules but norms. Still, it seems that there are private rules, such as think of this if you think of that, or rules of rational reasoning. Even if Wittgenstein has in mind public rules, these private rules seem possible and Wittgenstein seems wrong. But if Wittgenstein accepts private rules 
of rationality, but just does not call them 'rules,' then what he says remains interesting, but it does not have as its concern deep matters of what it is to think or to reason.

\section{Private Languages}

Let us return to language, which is where we came in.

Would Wittgenstein classify apparent 'rules' for private languages as 'rules' in the sense he is interested in (\$258)? I am not sure. Wittgenstein is interested in how the connection between words and private mental states is to be set up. Whether this counts as a rule is less interesting. Rule or not, can it be done? 'Yes', I say. And I say that Wittgenstein also says 'Yes', although I shall not argue this here. (See Zangwill 2011/2015, and in preparation.)

On the general issue of the connection between rules and language, we should probably see Wittgenstein as denying a general connection between the two. Language does not depend on rules and many rules do not concern language. (Chomskyan grammatical rules would not have concerned him.)

Language generally does not depend on rules for Wittgenstein. Mauro Englemann has pointed out that this was one of Piero Sraffa's important contributions to the Philosophical Investigations (Englemann 2011, 2013). Nevertheless, when a new language is introduced, self-consciously, as opposed to culturally evolving, it needs to be set up by means of an explicit rule. A private language is such an introduced language (see §258). So corresponding to a private language, there are rules, since the introduced language is set up by rules concerning inner ostensive definition. These rules may be private rules, not quite in the sense in which there are rules of rationality, but in the sense of linking a sensation type with the deployment of a linguistic physical type (a word). Where both antecedent and consequent of the rule are public, a rule is public. Where both antecedent and consequent are private, the rule is private. Where one is public and the other is private, I shall say that the rule is a 'hybrid' rule. Where one of the two items connected in the rule is a symbol-a sound or mark — which is to be deployed in some way given a mental state that one has, it is a hybrid rule, since it connects something private with something public - the perceivable symbol. By contrast, purely private rules connect two private items. Private language rules are hybrid rules. Most linguistic rules are public since the word (as physical token) is one public thing and the reality that corresponds to that public thing is another public thing, property or fact. There is no reason to think that there cannot be hybrid rules when one of the items in the rule 
is public and the other is private. Such a rule might be: if you see a red post box, then think of a sheep. Or consider the children's party song: "If you're happy and you know it clap your hands". The first is a public-private rule and the second is a private-public rule. What of private language? This seems to fall into the same category as: "If you're happy and you know it clap your hands". It is the hybrid rule: if, after associating an outer symbol " $\mathrm{S}$ " with an inner sensation type, you introspectively reidentify another instantiation of that inner sensation type, then utter the same word "S". No problem!

In my view, Wittgenstein nowhere commits himself against the possibility of such stipulated rules for private language. The question of private rules is a different one, and he does deny their possibility in $\$ 202$. But, as we saw, he means something special by a 'rule'. And once rules and language are disconnected, there are no implications for private language from what he says about private rules. What the inner ostension achieves is not a rule in Wittgenstein's public sense-instead it is a mini intra-personal institution or linguistic habit, which can be stable enough, given a reliable memory, to set up meaningful private language, one in which a terms refers to private mental states or events. But this language is useless in the sense that it cannot be used for interpersonal communication. (Wittgenstein distinguishes use from meaning at §43.) The introduced private language is useless but it is not meaningless ${ }^{2}$. 


\section{Notes}

${ }^{1}$ Professor of Philosophy at Hull University, England, U.K. e-mail: Nick.Zangwill@hull.ac.uk

${ }^{2}$ Thanks for written comments from Mauro Engelmann and conversations with Dawn Wilson. 


\section{References}

Boghossian, Paul. 2012. "What is Inference?", Philosophical Studies, Volume 169, Issue 1, pp 1-18

Chomsky, Noam. 1966: Cartesian Linguistics: A Chapter in the History of Rationalist Thought, New York: Harper \& Row.

Englemann, Mauro Luiz. 2011. "Wittgenstein's 'Most Fruitful Idea' and Sraffa", Philosophical Investigations 26: 155-178.

Englemann, Mauro Luiz. 2013. Wittgenstein's Philosophical Development: Phenomenology, Grammar, Method, and the Anthropological View, London: Palgrave.

Gentzen, Gerhard. 1935. "Untersuchungen über das logische Schliessen" ("Investigations into Logical Deduction"). Mathematisches Zeitschrift 39: 176-210, 405-431. Reprinted in The Collected Papers of Gerhard Gentzen. Amsterdam: North Holland, 1969.

Hacking, Ian. 1979. "What is Logic?”, Journal of Philosophy LXXVI: 285-319.

Kneale, William. 1956. “The Province of Logic.” In H. D, Lewis (ed.), Contemporary British Philosophy, 237-261, London: George Allen and Unwin.

Kripke, Saul. 1982. Wittgenstein on Rules and Private Language, Cambridge, Mass: Harvard University Press.

Wittgenstein, Ludwig. 1982. "Philosophy", in Wittgenstein's Lectures Cambridge 1932-35, from the Notes of Alice Ambrose and Margaret Macdonald, Blackwell: Oxford,.

Wittgenstein, Ludwig. 2008. Philosophical Investigations, Oxford: Blackwell.

Wittgenstein, Ludwig. 1992. Last Writings on the Philosophy of Psychology, volume 2: The Inner and the Outer, Oxford: Blackwell.

Zangwill, Nick. 2005. "The Normativity of the Mental”, Philosophical Explorations 8: 1-20.

Zangwill, Nick. 2010. "Normativity and the Metaphysics of Mind", Australasian Journal of Philosophy.

Zangwill, Nick. 2011. "Music, Essential Metaphor and Private Language", American Philosophical Quarterly 48.1.

Zangwill, Nick. (in preparation). "Wittgenstein on Private Language". 